\title{
Learning analytics experience among academics in Australia and Malaysia: A comparison
}

\section{Deborah West}

Flinders University, Australia

Zaidatun Tasir

Universiti Teknologi, Malaysia

Ann Luzeckyj

Flinders University, Australia

Si Na Kew

Universiti Teknologi Malaysia

Danny Toohey

Murdoch University, Australia

Zaleha Abdullah

Universiti Teknologi Malaysia

Bill Searle

Charles Darwin University, Australia

Nurul Farhana Jumaat

Universiti Teknologi Malaysia

Richard Price

Flinders University, Australia

Several studies have been conducted to evaluate the experience and involvement of academics in learning analytics (LA) due to its potential for improving teaching and learning. However, findings often reflect an educational culture which is indicative of the institutional or national context where the study has occurred, resulting in bias regarding LA perspectives. Therefore, this study seeks to compare and contrast the experiences of LA among academics in Australia and Malaysia, with intentions to learn from each other's experience. Areas of comparison were: (1) academics' involvement in LA activities; (2) academics' responses to the institutional capacity in supporting LA; and 3) academics' concerns about the ethical issues surrounding LA. A survey of 353 Australian and 224 Malaysian academics revealed similarities and differences. It is evident from these results that the context and infrastructure for LA are at different stages of development in both countries. Nevertheless, the results provide an interesting reflection on academics' needs, institutional understanding, policies, and educational cultural biases in applying LA in teaching and learning in higher education institutions.

\section{Introduction}

The last few years have marked continuous development of LA to support improvements in higher education. Extensive work has been undertaken in relation to broader considerations in the field including frameworks for LA development and implementation (Colvin et al., 2016; Drachsler \& Greller, 2012; Jisc, 2017; West, Heath \& Huijser, 2016; West, Huijser, Lizzio et al., 2016), evaluating perception and confidence in LA (Drachsler \& Greller, 2012), identification of appropriate datasets and data integrity (Dyckhoff, Zielke, Bultmann, Chatti, \& Schroeder, 2012; Jisc, 2015a), and ethical and legal issues (Drachsler \& Greller, 2016; Jisc, 2015b; Scholes, 2016; Sclater, 2016; West, Huijser, \& Heath, 2016). In the context of the application of LA, a great deal of work has also occurred in relation to determining the 
indicators of at-risk students (Lawson, Beer, Rossi, Moore, \& Flemming, 2016), designing tools to capture, analyse, and visualise students' profiles and learning engagement (Ferguson, 2012), and constructing specific pedagogical designs that are aligned with LA data and teaching and learning objectives (Corrin et al., 2016; Koh, Shibani, Tan, \& Hong, 2016; Martin \& Whitmer, 2016; Rodriquez-Tirana, Martinez-Mones, Asensio-Perez, \& Dimitriadis, 2015).

Despite these ongoing developments in LA, there remain issues that influence the acceptance and implementation of LA, and the activities remain far from being understood and supported among academics in higher education institutions. The issues which potentially undermine the progress of LA include: questions regarding its goals and intended outcomes which can affect the educational practice or learning design in certain areas (Greenhow \& Gleason, 2014; Mor, Ferguson, \& Wasson, 2015); the competencies required of academics to interpret data while continuing to manage and control the learning process (Corrin et al., 2016); appropriate and applicable actions that can be taken by academics based on the educational data available in the institution's data systems and appreciating how this data may best be used (Bennett, Agostinho, \& Lockyer, 2015); and barriers of concern such as ethics, privacy rights, and policies on data usage (Drachsler \& Greller, 2012; Ifenthaler \& Tracey, 2016; West, Heath, \& Huijser, 2016). Many of these issues are likely to be influenced by cultural factors in various institutions, countries and education systems yet there is very little acknowledgement of the importance of these differing contexts.

While some of the literature to date has drawn attention to the essential role of context in LA development (Ferguson, Macfadyen, Clow, Tynan, Alexander, \& Dawson, 2014; Gasevic, Dawson, Rogers, \& Gasevic, 2016; Mor et al., 2015; West et al., 2016), this aspect has been largely under-researched and/or not made explicit in research that has taken place. In relation to LA, context relates to the various levels of cultural influences including within institutions, regions, countries as well as educational systems, learning and research paradigms and approaches, all of which are inter-related and dynamic. For example, many of the projects (e.g., PAR Framework in United States [http://www.parframework.org/], LACE project in Europe [http://www.laceproject.eu/faqs/learning-analytics/\#]) were based on a single cultural research approach. Due to the unstated cultural biases, it is difficult to accurately interpret results from different cultural perspectives. It should be noted that generalisations made from one cultural context cannot be transferred if they do not take into account the other's educational culture, methodology, and ethical factors (Escotet, 2015).

This article provides a comparison of findings of a collaborative project between Australia and Malaysia. The focal point of this comparison is three-fold:

1. academics' involvement in LA activity,

2. academics' responses to the institutional capacity in supporting LA, and

3. academics' concerns about the ethical issues surrounding LA.

Focusing on these areas, this comparison project aims to provide indicative insights, which can enrich the understanding of the inconsistencies that might exist between academics' experience and their needs to allow LA to function usefully across a range teaching and learning environments. The paper begins with a brief background to set the scene followed by an outline of the research questions that motivated the comparison. The methodology used for this project is then explained and the results presented followed by a discussion about the findings. Finally, the conclusions and limitations are summarised.

\section{Background}

Looking at LA development internationally, it has been highlighted that different countries and regions are at different stages of development (Sclater, Peasgood, \& Mullan, 2016). Australia and the USA are seen as leaders in the field with the United Kingdom and Europe closely behind (Sclater et al., 2016). The road to LA development relies on various factors, as is demonstrated in the work on LA development and implementation frameworks (Drachsler \& Greller, 2012; Colvin et al., 2016; Jisc, 2017; West, Heath, \& Huijser, 2016; West, Huijser, Lizzio et al., 2016) but of particular importance to our discussion are the roles of context more broadly, infrastructure and strategic drivers. Context broadly should be seen to include the disciplinary, institutional, local, national, and regional nuances that impact on all aspects of the work undertaken in relation to LA. This in turn impacts on the strategic drivers and the infrastructure available and as such this context element is highlighted and embedded in the discussion below. 
By definition, LA relies on digital data that is captured in systems related to the educational journey including learning and teaching interactions. LA development is therefore premised on key infrastructure to capture data and the use of educational technology to understand learning and teaching transactions. However, the use of educational technology varies between institutions, countries and regions. As such, much of the data that is available in systems in Australia is very different from that available in Malaysian systems. These differences influence the priority that is given to LA work, the investment that is made, and the way that LA develops and expands in the two countries.

There are also different strategic drivers across international education systems that impact on LA. For example, in Australia, a government driven initiative in recent years has involved widening participation in higher education focussed on encouraging students who previously would not have attended university (e.g., those from lower socio-economic groups, indigenous and culturally diverse backgrounds etc.) to enter the system (Australian Government, 2009). An associated aspect of the initiative that has affected LA research has been an increased emphasis on student success and student retention. Institutions have explored ways to support diverse student cohorts through changes to learning and teaching approaches, support mechanisms and better reporting. Much of the LA work in Australia has reflected this driver and has focused on identifying 'at risk' students, seeking ways to personalise the learning journey and improve student success. In contrast, Malaysia is at an early stage of exploring the potentialities of LA to support student retention. The Ministry of Higher Education in Malaysia is planning to focus on LA to reflect the need to transform teaching and learning in higher institutions shifting the focus from retention to better cater to current industry changes which incorporate digital technologies known as the Fourth Industrial Revolution.

Student success more broadly is also connected to national drivers (present in many countries) related to graduate outcomes and employability which are often used as indicators of institutional standing. The need to fulfil the demands of the institution in producing nationally and globally competitive graduates (Roberts, Howell, Seaman, \& Gibson, 2016) could explain the rapid expansion of LA without the involvement of all stakeholders, including but not limited to academics.

In the United Kingdom, the work of Jisc (formerly the Joint Information Systems Committee) has made considerable progress on LA with the establishment of a national learning analytics service for higher and further education. This is the first time learning analytics have been deployed at a national level anywhere in the world. Working and collaborating with 50 universities, Jisc has developed a suite of resources, tools and guides to support the implementation of LA in the UK (Jisc, 2017). The Effective Leaning Analytics Project, commissioned by Jisc in 2014 and concluded in September 2017, provides a basic learning analytics solution and resources to help the take up of learning analytics. This work has been complimented by the work that Jisc has undertaken in developing a code of practice for learning analytics (Jisc, 2015) which sets out the responsibilities of educational institutions to ensure that learning analytics is carried out responsibly, appropriately, and effectively. From current practice in the UK and internationally, Jisc anticipates that LA could make significant contribution as a tool for; quality assurance and quality improvement; boosting retention rates; assessing and acting on differential outcomes for students; and as an enabler for the introduction of adaptive learning.

A more comparative project undertaken in Europe, The State of Learning Analytics (Tsai \& Gasevic, 2017), solicited input from a range of stakeholders about institutional readiness for LA from higher education institutions. The report findings from interviews conducted with 51 institutions across 61 countries shows that 21 out of 51 institutions had implemented centrally-supported learning analytics projects, 9 of which had reached institution-wide adoption, 7 partial-level (inclusive of pilot projects), and 5 were at the data exploration stage. In the interim 18 institutions were in preparation to roll out institutional learning analytics projects, and 12 did not have any concrete plans for an institutional learning analytics project yet. Survey results revealed that 15 institutions had implemented learning analytics, of which 2 had reached full implementation and 13 were in small scale testing phases. Sixteen institutions were in preparation for learning analytics projects, and 15 were interested but had no concrete plans yet. 
The report findings show that both the survey and interviews revealed an intertest in LA with two-thirds of institutions either having implemented LA or intending to do so. The drivers and motivations emphasised for the adoption of LA identified three common aspects of internal drivers for the adoption of LA:

1. Learner-driver: to encourage students taking responsibility for their own studies by providing databased information or guidance.

2. Teaching-driver: to identify learning problems, improve teaching delivery, and allow timely, evidence-based support.

3. Institution-driver: to inform strategic plans, manage resources, and improve institutional performances, such as retention rate and student satisfaction.

While many tools have been created, aiming to benefit academics and students by improving access to information about their teaching and learning, few appear to have explored or report on what academics actually want. However, a study at the University of Melbourne conducted a series of focus groups involving 29 academics across disciplines (law, engineering, and education) and degree levels. They revealed the five categories of teaching and learning problems or situations that were seen by the academics to be useful for future work in LA (Corrin, Kennedy, \& Mulder, 2013). The categories identified were:

1. student performance,

2. student engagement,

3. the learning experience,

4. quality of teaching and the curriculum, and

5. administrative functions associated with teaching.

Several academics also pointed out that they had attempted to use LA to support their teaching, however, their needs were not met by the data representations currently available in the system, and there was no way to access and extract the required data in a useful, operational format, nor to customise the outputs of the system in order for them to be useful for the individual (Corrin et al., 2013). Additionally, little is known about academics' views of the potential ethical issues associated with LA (Rodriguez-Triana, MartinezMones, \& Villagra-Sobrino, 2016). The main ethical issues in relation to LA have been identified as privacy, consent, and the way data are used, acted upon, stored, and protected (e.g., Cumbley \& Church, 2013; Rubel \& Jones, 2016). Some researchers have shown interest in the ethical issues associated with LA, and have suggested ways to facilitate a trusted implementation of LA. Their suggestions have included: the use of an ethical decision-making framework (West, Huijser, \& Heath, 2016), developing a set of design guidelines (Pardo \& Siemens, 2014), and an ethics checklist for academics, researchers, policy makers, and institutional top management teams (Drachsler \& Greller, 2016). Nevertheless, these guidelines would seem more appropriate at the institutional level rather than the teaching context (Rodriguez-Triana et al., 2016). Rodriguez-Triana et al. (2016) therefore make several recommendations regarding how LA could be conducted ethically at the teacher level.

In terms of research approaches and epistemologies, much of the work that is commonly published and cited in relation to LA emerges from a largely western paradigm. This presents an unstated bias in terms of how things are investigated, understood and reported as well as how students might learn in different cultural contexts. These biases in studies are crucial because they imply differences in and possible disengagement between what has been reported in the literature and the actual needs of academics with regard to how LA can be executed practically to improve educational outcomes.

In summary, the background studies presented here highlight the importance of gathering insight to academics' needs and concerns regarding the overall potential and usefulness of LA in higher education in different cultural contexts. Therefore, the development of the survey instrument and design of the current study has taken into account and attempted to address the aforementioned limitations of other studies. Our study explores the views of academics in relation to their knowledge and engagement in LA initiatives and how they are supported by their institutions in the use of LA. Additionally, this collaborative study between Australia and Malaysia, allows an examination of commonalities and differences in educational culture, thus ensuring that LA practices are developed in ways that are acceptable across the education cultures of different nations. 


\section{Research questions}

This study is guided by three main research questions that aim to highlight the comparison among Australian and Malaysian academics’ views on LA in relation to student retention:

1. What are the related LA activities that academics in Australia and Malaysia have been involved and interested in?

2. What are the Australian and Malaysian academics' responses to the institutional capacity in supporting LA?

3. How concerned are Australian and Malaysian academics about the ethical issues surrounding LA?

\section{Methodology}

\section{Establishment of an international collaborative research project}

The Use of Learning Analytics to Support Improvements in Teaching Practice is an international collaborative project run between the Innovative Research Universities (IRU) and the Malaysian Research Universities Network (MRUN). It is jointly funded by the IRU and the Ministry of Higher Education of Malaysia. The research team consists of partners from Charles Darwin University (lead institution in Australia), Flinders University, Murdoch University, Universiti Teknologi Malaysia (lead institution in Malaysia), and Universiti Kebangsaan Malaysia. The project aims to explore academics' perspectives on the use of LA to support improvements in teaching practice in relation to student retention and success. One of the objectives of this project is to identify the range of LA functions available in partner institutions which are related to teaching practice.

The first stage of the IRU/MRUN project draws on the findings and utilises the research instruments of the Australian Government Office for Learning and Teaching funded project, Learning Analytics: Assisting Universities with Student Retention (West, Huijser, \& Heath, 2016), A core component of that project was an academic level survey consisting of a range of questions related to the interest, view on and use of LA. Findings related to this project have been disseminated widely (West, Heath, \& Huijser, 2016; West, Huijser, \& Heath, 2016; West, Huijser, Lizzio et al., 2016), including in a previous AJET publication (West, Huijser, Heath et al., 2016).

Utilising the academic survey from the previous project, the IRU/MRUN project sought to compare academic views in Malaysia and Australia. This article therefore utilises a subset of data from the Australian project as previously published in AJET (West, Huijser, Heath et al., 2016), however this is now presented in comparison to Malaysian data. The main focus of the current article is to explore this international comparison and perspective.

The next subsection sets out information about the instrument, the respondents, and the distribution process.

\section{Instrument, respondents and the distribution process}

The academic level survey, developed by the Australian universities’ partners as part of the Australian Government Office for Learning and Teaching funded project, Learning Analytics: Assisting Universities with Student Retention (West, Huijser, \& Heath, 2016), consists of a range of questions related to the interest, view on and use of LA by academics. Questions were designed using a variety of scaling techniques, including Likert scales, single and multiple responses, and open-ended questions. Examples of the Likert scales used are as follows: (1) no interest, a little interest, interested, a lot of interest, not sure; (2) very poor, poor, fair, good, very good, not sure; (3) no concern, low concern, not sure, concern, high concern; and (4) daily, weekly, fortnightly, monthly, less than monthly, never.

The Malaysian partners later adapted the survey and made some minor modifications, based on the discussion among the research teams, the findings from the pilot study, and experts' validation, to suit the Malaysian teaching and learning setting. The accommodations made to the survey in Malaysia emphasised the significance of language, context and maturity regarding LA and online learning and teaching. Arising from discussions with Malaysian colleagues it became evident that very few institutions in Malaysia utilised an LMS to support learning and teaching and subsequently limiting the understanding of LA in this context. 
Modification to the survey in Malaysia were made on this premise. Reliability testing of the survey was also conducted using a Rasch Analysis technique (to comply with the survey's use of single and multiple responses), and the Cronbach's alpha (KR-20) value was 1.00 indicating that the survey had a high reliability value (Linacre, 1991).

In Australia, the survey was conducted between September and November 2014 and targeted academic staff (e.g., teachers, student support, academic developers etc.), through a purposive, snowball sampling strategy to recruit self-selecting individuals $(n=353)$, whose responses were anonymous. Responses were received from the institutions in Australia $(n=341)$ and extended to New Zealand $(n=10)$. The questionnaire was hosted using the online Qualtrics application, and invitations were promoted via existing networks, professional associations, and conferences.

In Malaysia, the survey was administered between August and December 2016, and was aimed at academic staff (e.g., lecturer), through a purposive sampling method $(n=224)$. The responses received spanned 33 institutions (local, $n=21$; private, $n=12$ ) in Malaysia. The questionnaire was delivered online using Survey Monkey, and invitations were sent to existing networks via email and Facebook, while some were distributed manually during an exhibition on e-learning technology. For the purpose of this article, only seven questions in the survey were used for the comparison. The selected questions are tabulated in Table 1.

In addition, a series of semi-structured interviews were conducted with respondents who had completed the academic level survey and who were interested in being interviewed. The aim of the interviews was to gain a better understanding of some of the key elements and issues found in the survey. In Australia, the interviews were conducted between December 2014 and February 2015, with 23 people from 15 different universities. Participants held a variety of roles (e.g., teacher, educational developer, student support officer, librarian, LA project leader, tutor, and learning and teaching leader) and spanned different academic levels. Meanwhile, in Malaysia, the interviews were conducted between February 2017 and March 2017, with 12 academic staff from 6 institutions. Each interview was digitally recorded and manually transcribed and coded by two researchers.

Table 1

Research questions and key points of survey

\begin{tabular}{|c|c|}
\hline Research questions & Key points of the survey \\
\hline $\begin{array}{l}\text { What are the related LA activities } \\
\text { that academics in Australia and } \\
\text { Malaysia have been involved and } \\
\text { interested in? }\end{array}$ & $\begin{array}{l}\text { 1. Interest in LA application that can be linked with student } \\
\text { retention and success } \\
\text { 2. Involvement in LA related activity } \\
\text { 3. Participation in LA discussion }\end{array}$ \\
\hline $\begin{array}{l}\text { What are the Australian and } \\
\text { Malaysian academics' perceptions of } \\
\text { institutional capacity in supporting } \\
\text { LA? }\end{array}$ & $\begin{array}{l}\text { 4. Access to data sources relating to the student journey } \\
\text { 5. Professional development attendance status } \\
\text { 6. Institution's capacity in meeting academics' needs and } \\
\text { expectations }\end{array}$ \\
\hline $\begin{array}{l}\text { How concerned are Australian and } \\
\text { Malaysian academics about ethical } \\
\text { issues surrounding LA? }\end{array}$ & 7. Level of concern on LA ethical issues \\
\hline
\end{tabular}

Table 2 shows the distribution of the demographic data of Australian and Malaysian respondents. Despite the small sample of respondents, it can be said that the heterogeneity of the respondents is acceptable in regard to the teaching experience and teaching role. 
Table 2

Demographic data distribution about Australian and Malaysian respondents ( $n$ varies)

\begin{tabular}{llcccc}
\hline Variable & Category & \multicolumn{2}{c}{ Malaysia } & \multicolumn{2}{c}{ Australia } \\
\cline { 3 - 5 } & & Frequency & $\begin{array}{c}\text { Percentage } \\
\mathbf{( \% )}\end{array}$ & $\begin{array}{c}\text { Frequency } \\
\text { Percentage } \\
\text { (\%) }\end{array}$ \\
\hline Academic level & Associate Lecturer/ & 13 & 5 & 30 & 9 \\
(Malaysia, $n=224$ & Tutor & & & & \\
Australia, $n=351$ ) & Lecturer & 49 & 22 & 124 & 35 \\
& Senior Lecturer & 103 & 46 & 88 & 25 \\
& Associate Professor & 32 & 14 & 30 & 9 \\
& Professor & 17 & 8 & 20 & 6 \\
\hline Length of & Other & 10 & 5 & 59 & 17 \\
employment in & Less than 1.5 years & 19 & 8 & 11 & 3 \\
higher education & 1.5 - 5 years & 36 & 16 & 42 & 12 \\
sector & 11 - 20 years & 44 & 20 & 85 & 25 \\
(Malaysia, $n=223$ & More than 20 years & 86 & 39 & 130 & 38 \\
Australia, $n=353)$ & & 38 & 17 & 77 & 22 \\
\hline Involvement in & Teaches students & 190 & 99 & 276 & 78 \\
teaching students & Does not teach & 1 & 1 & 77 & 22 \\
(Malaysia, $n=191$ & students & & & & \\
Australia, $n=353)$ & & & & & \\
\hline
\end{tabular}

\section{Results}

\section{Research question 1: What are the related LA activities that academics in Australia and Malaysia have been involved and interested in?}

The survey results focus on three specific areas of LA application: interest in LA application; involvement in LA-related activity; and participation in LA discussions. Each area is discussed in more detail below.

Interest in LA application that can be linked with student retention and success

As interest in the use of LA has developed, its use and application in teaching and learning has also grown. As discussed earlier, one area of this growth, especially in Australia due to a government policy on widening participation, has related to student retention and success. Hence, this survey also aimed to investigate the academics' interest in this applicaton of LA. Figure 1 reveals the findings.

Out of the 10 choices of LA application, 7 types of applications received responses with more than 50 percent agreement from academics in both countries. These include: (1) students monitoring own progress and identifying actions they could take; (2) identification of at-risk students with a view to staff responding to address the risk; (3) teaching staff evaluating and improving their program curriculum; (4) informing design and layout of online learning sites and environment; (5) program teams evaluating and improving their program curriculum; (6) informing potential initiatives to promote student retention; and (7) development of broad knowledge base about how effective learning can occur. The number of responses varied in a range of 141 - 143 and 311 - 317, in Malaysia and Australia respectively, due to missing data. The findings need to be interpreted thoughtfully since academics had a choice to select from among no interest, a little interest, and not sure options. Those options were not included in Figure 1. 


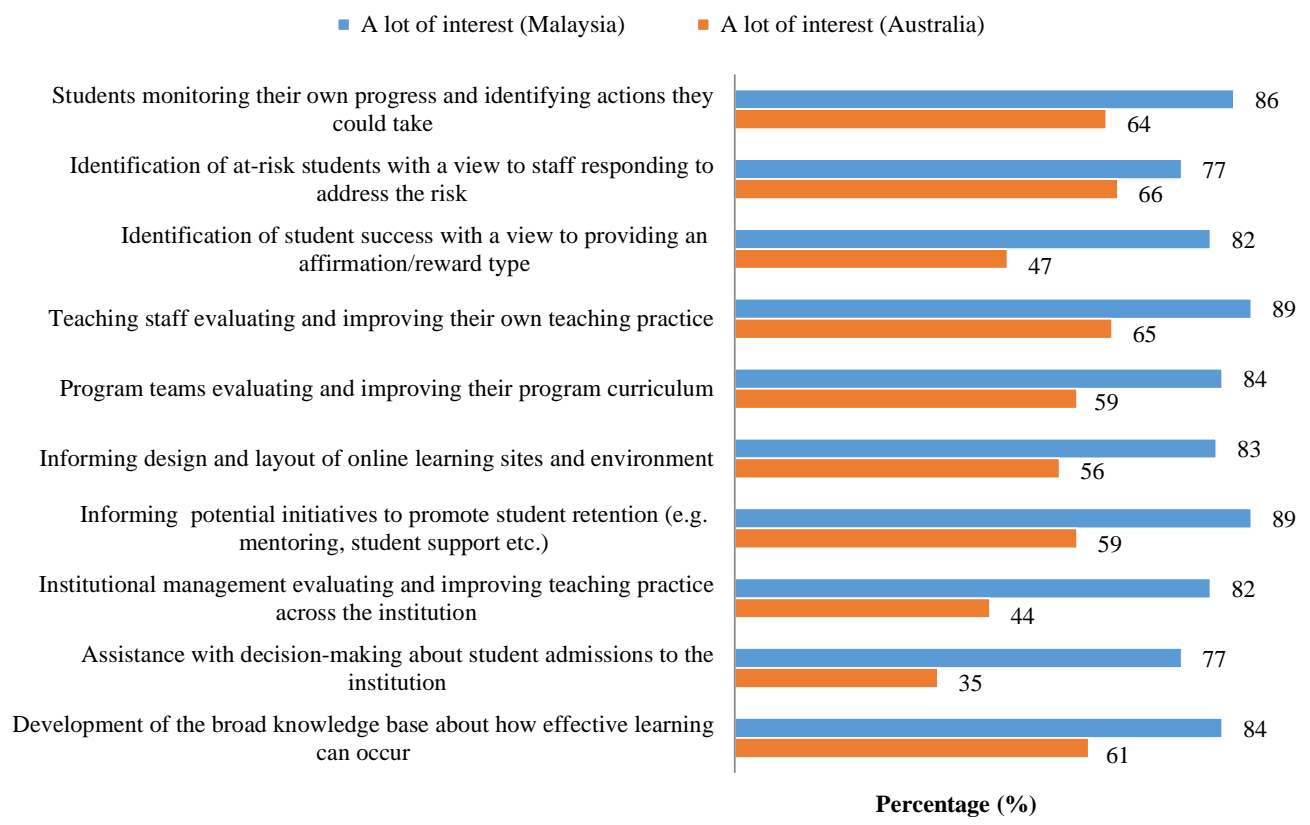

Figure 1. Percentage distribution of Malaysian and Australian academics' interest in LA application that can be linked to student retention and success ( $n$ varies)

Involvement in LA related activity

Academics were asked about their involvement in any LA-related activities. The results presented in Table 2 can be summarised in two key points. Firstly, not much difference can be noted in academics' involvement in types of LA-related activity in both countries. Secondly, academics in this study were more likely to be involved in activities focussed on building their own capacity and practice (e.g., reading about LA for own professional development, using LA for analysis and decision making) rather than sharing with others (e.g., delivering training on LA, advocating the use of LA to colleagues, being part of a group that conduct LA at institutions).

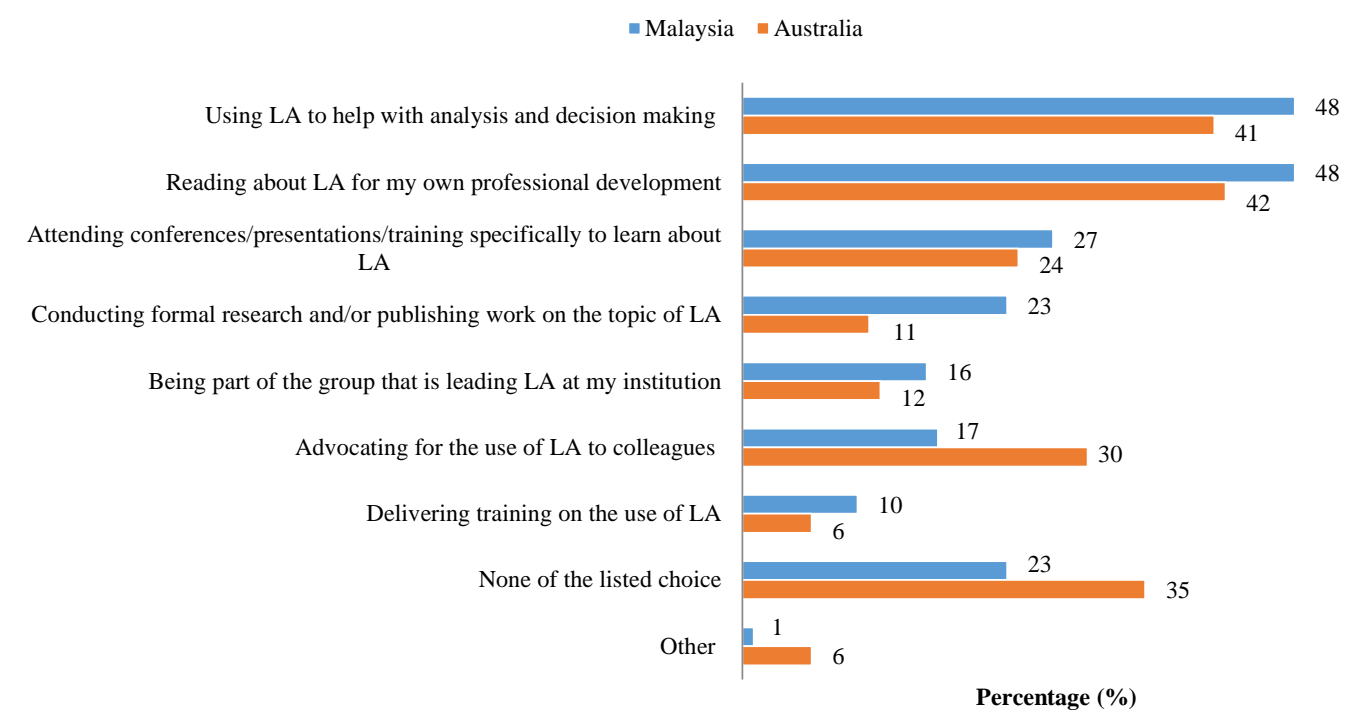

Figure 2. Percentage distribution of Malaysian and Australian academics' involvement in LA-related activity (Malaysia, $n=146$; Australia, $n=346$ ) 
Participation in LA discussion

Academics were also asked about their engagement level in LA discussions (in terms of frequency) with their colleagues in the institution. Figures 3 and 4 display the results.

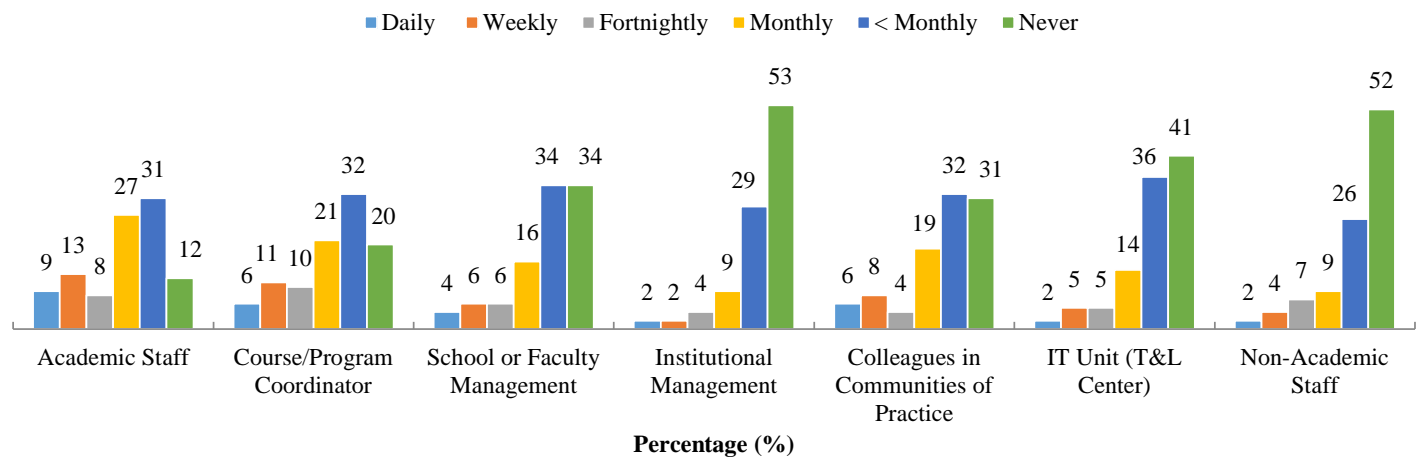

Figure 3. Percentage distribution of Malaysian academics’ participation in LA discussion ( $n$ varies)

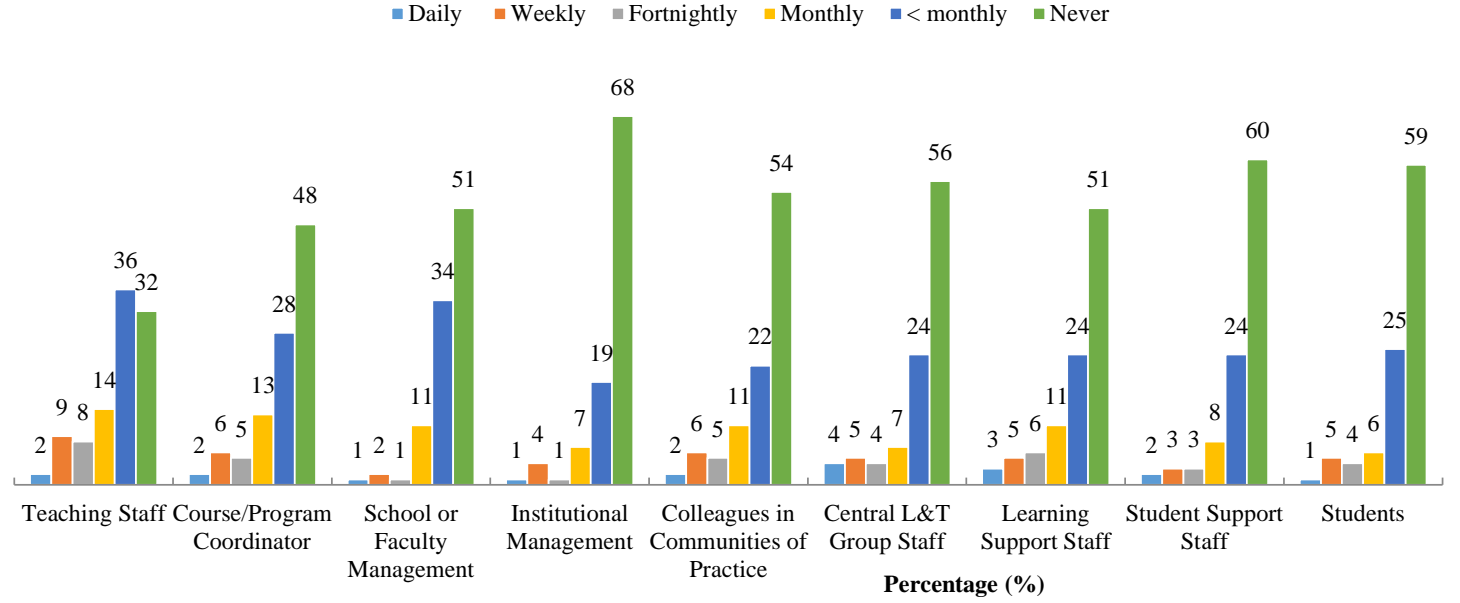

Figure 4. Percentage distribution of Australian academics' participation in LA discussion ( $n$ varies)

It should be noted that the findings regarding Malaysian and Australian academics' participation in LA activities were not combined into one figure as the category of role was not the same in both countries and may carry different meanings, which could affect the responses and interpretations. The findings show that academics in both Malaysia and Australia often have discussions about LA with academic staff/teaching staff and have less frequent discussions with the institutional management. Due to missing data, the number of responses varied between 133 - 145, and 296 - 319, in Malaysia and Australia, respectively.

\section{Research question 2: What are the Australian and Malaysian academics' responses to the institutional capacity in supporting LA?}

LA requires key infrastructure to capture, integrate and present relevant data to stakeholders. In addition, appropriate professional development is necessary to ensure that academics are competent in being able to access, understand and use LA data. To obtain an idea of the current technology and support available for LA, we asked the academics to answer questions related to their institutional capacity in addressing the support provided to underpin LA.

Access to data sources relating to the student journey

Educational data may come from different sources and exist either as structured data and/or unstructured data. To identify the potential of educational data that can be beneficial to LA practice, academics were asked to indicate their access to data sources which stored data relating to the student journey. 


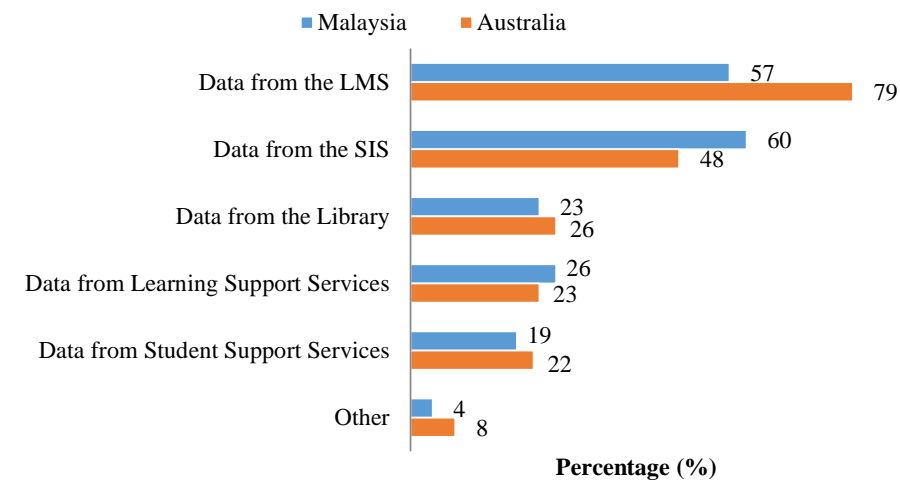

Figure 5. Percentage distribution in accessing data sources relating to the student journey among Malaysian and Australian academics (Malaysia, $n=176$; Australia, $n=352$ )

As illustrated in Figure 5, academics in Malaysia and Australia show an opposite finding regarding access to data sources that come from the Learning Management System (LMS) and Student Information System (SIS). It is notable here that Malaysian academics have higher access to data from SIS and lower access to data from LMS as compared to Australian counterparts. However, the percentage difference between accessing data sources from LMS and SIS among Malaysian academics was still small. On the other hand, academics from both countries were particularly unlikely to have access to other types of data sources such as Data from the Library, Data from Learning Support Services, and Data from Student Support Services.

\section{Professional development attendance status}

As mentioned earlier, appropriate professional development is necessary to ensure academics are competent in understanding and interpreting LA data and reports. Academics were therefore asked about the professional development provided by the institution and their attendance status. Again, the findings from the academics in both countries are shown separately (Figures 6 and 7) as the categories of attendance used were different. Generally, the results can be explained as follows: (1) all five types of professional development have been attended by less than 25 and 16 percent of academics in Malaysia and Australia, respectively; and (2) academics in both countries are interested in professional development related to LA, with more than half (Malaysia: between 57 and 59\%; Australia: between 84 and 87\%) indicating that they have attended or would attend professional development training if it was offered by their institution.

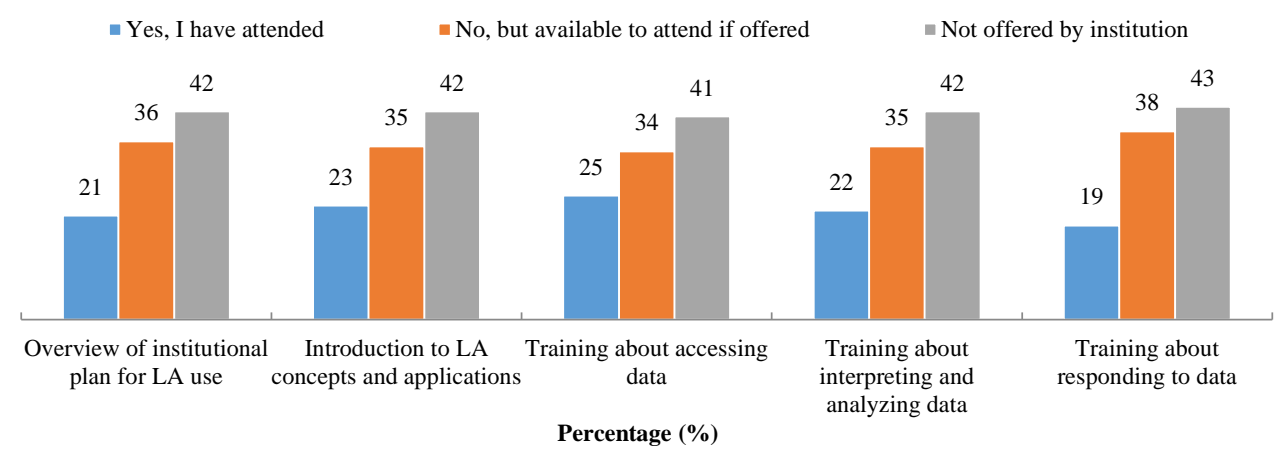

Figure 6. Percentage distribution of professional development in LA among Malaysian academics ( $n$ varies) 


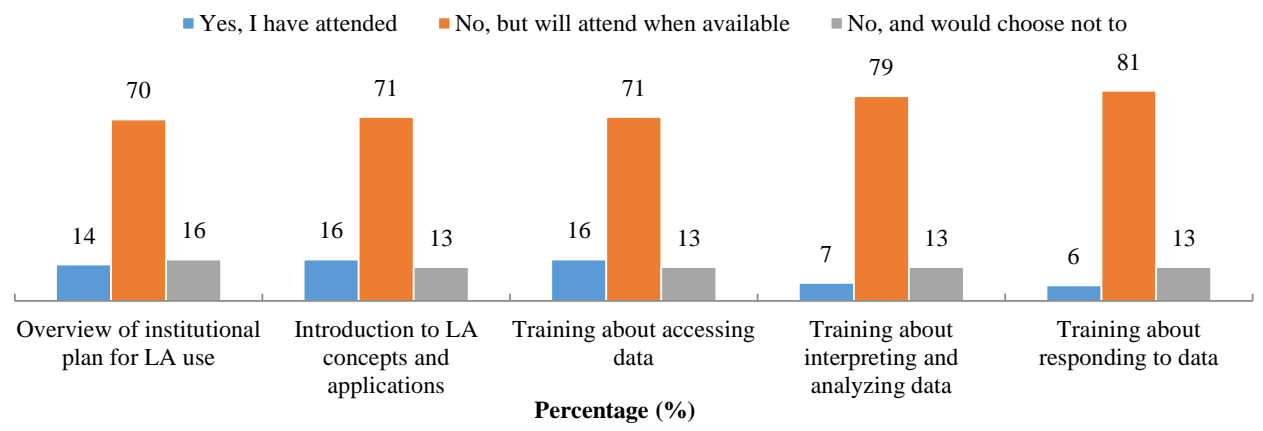

Figure 7. Percentage distribution of professional development in LA among Australian academics ( $n$ varies)

Institution's capacity in meeting academics' needs and expectations

Academics were asked about the extent to which the institution met their needs and expectations in regard to the selected provision of the application of LA. The findings for both countries are shown in separate figures (Figures 8 and 9) as a result of the different stages of LA development in both countries.

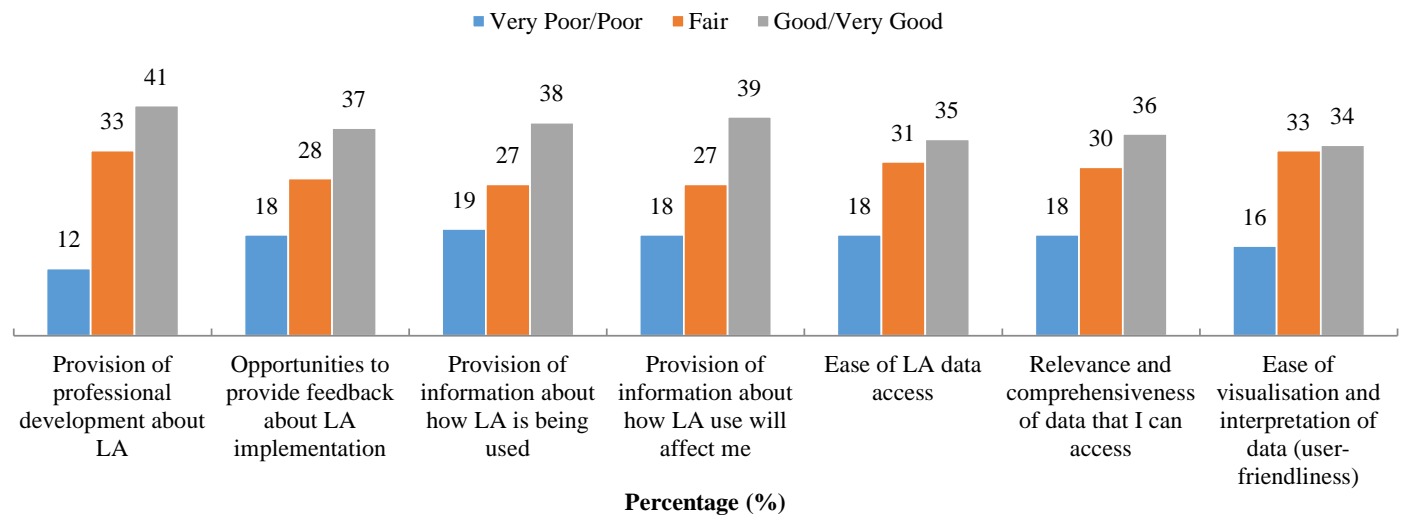

Figure 8. Percentage distribution of institutional capacity in meeting Malaysian academics' needs and expectations ( $n$ varies)

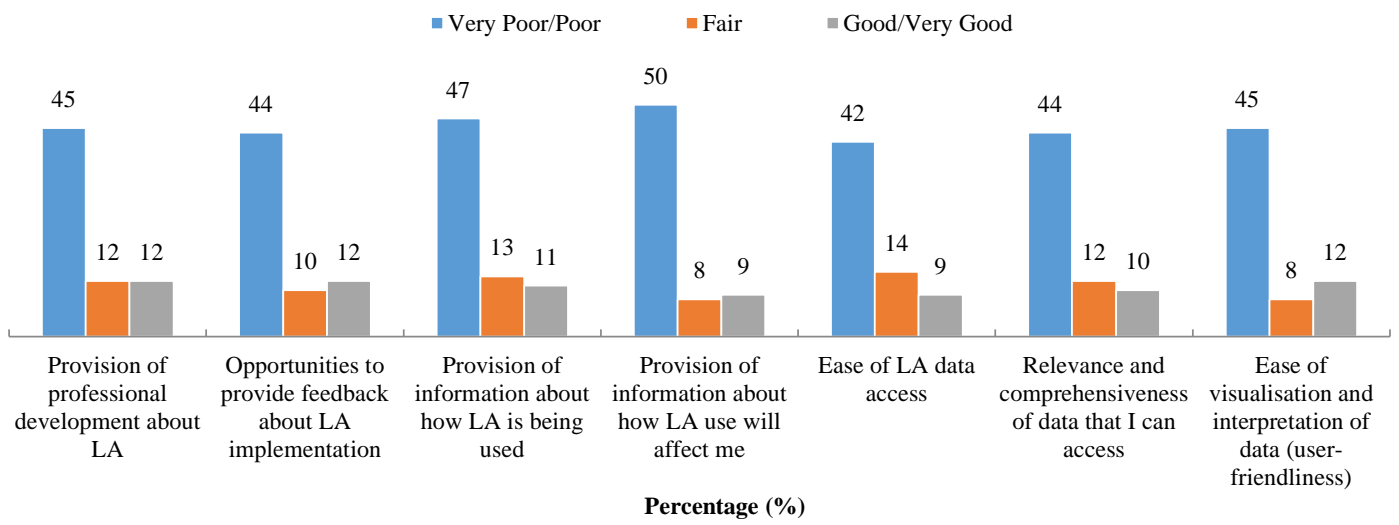

Figure 9. Percentage distribution of institutional capacity in meeting Australian academics' needs and expectations ( $n$ varies)

What is interesting is the differing perceptions held by academics in Malaysia and Australia regarding the institution's capacity to meet their needs and expectations concerning LA. Malaysian academics rated all seven provisions of application of LA as good/very good, whereas the Australian counterparts rated all the provision categories as poor/very poor. Nevertheless, each of the areas stated achieved a confidence level of less than $50 \%$. The findings require cautious interpretation since: (1) both countries are at a different stage of LA development and understanding; (2) academics were able to select the not sure option, which falls in the range of 15 to17\% in Malaysia and 29 to 36\% in Australia; and (3) due to missing data, where the number of responses varied between 135 - 136 in Malaysia and 289 - 292, in Australia. 


\section{Research question 3: How concerned are Australian and Malaysian academics on the ethical issues surrounding LA?}

While ethics is an area of focus in LA research the literature indicates academics' views regarding ethical issues associated with LA requires exploration. Hence, academics in this study were asked about the ethical concerns they felt would affect the adoption and acceptability of LA development which directly related to their teaching practice. Since the ratings used to indicate concerns were not the same in Australia and Malaysia, the findings are shown separately as presented in Figures 10 and 11.

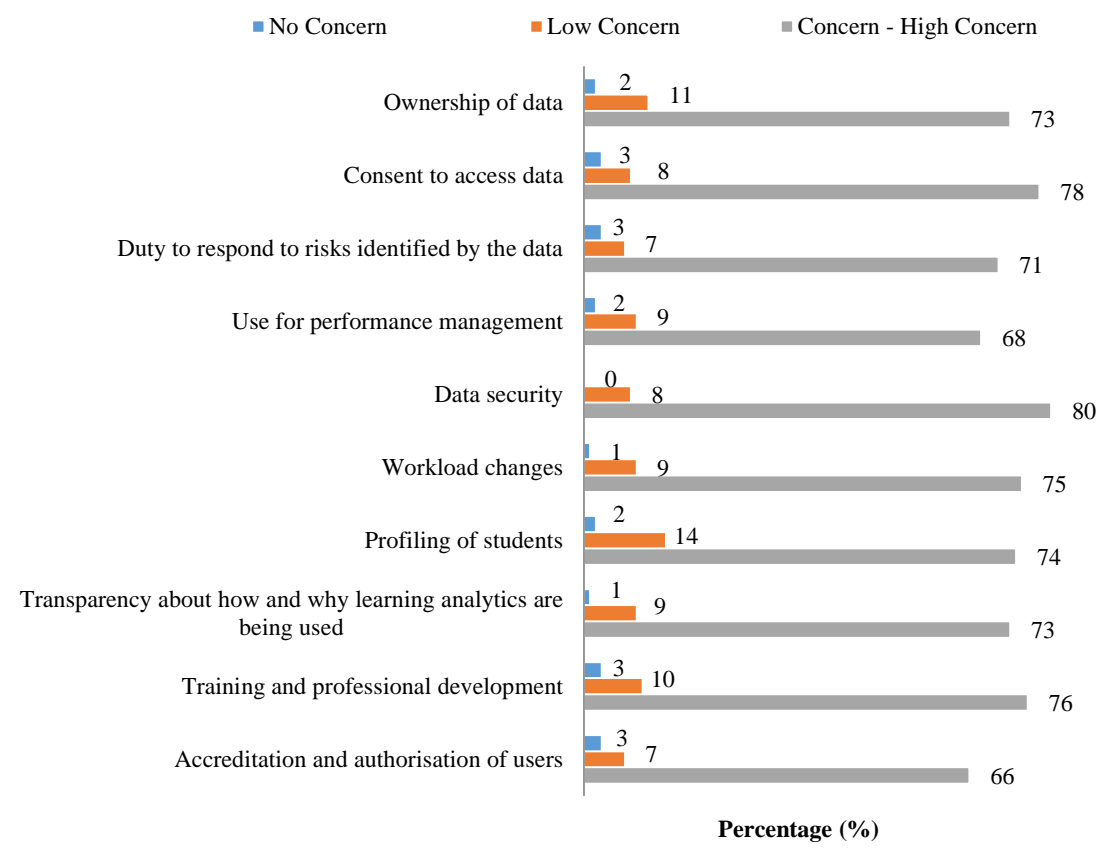

Figure 10. Percentage distribution on concern for ethics among Malaysian academics ( $n$ varies)

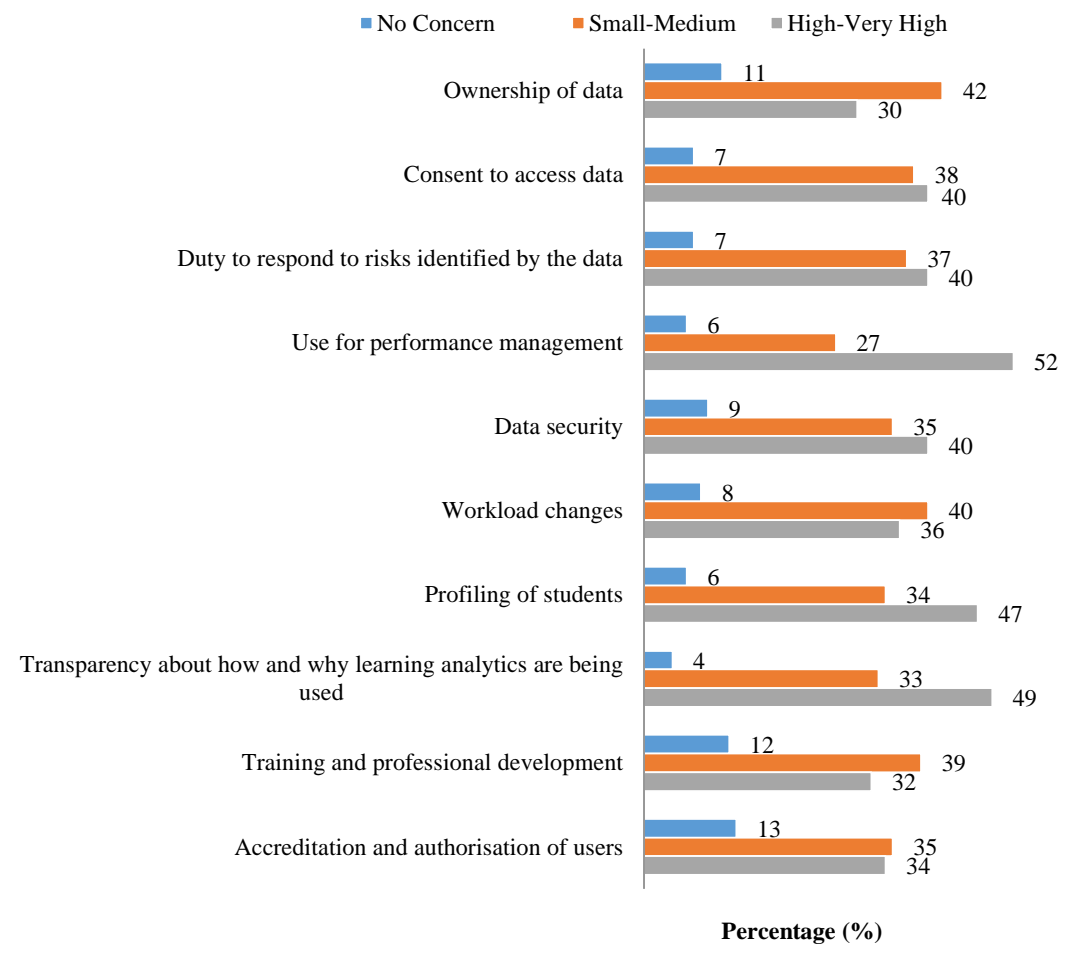

Figure 11. Percentage distribution on concern for ethics among Australian academics ( $n$ varies) 
It is evident that there were differences in ethical concerns across the two countries. In Malaysia, academics’ level of ethical concern was above 66 percent across all areas while in Australia the levels of ethical concern differed in relation to the specific aspect of ethical behaviour and only exceeded $50 \%$ in relation to the Use of performance management. Interpretation regarding this question requires caution as the percentage for 'not sure' for both countries (in a range of 11-20 percent in Malaysia and 14-18 percent in Australia) is somewhat high. Due to missing data, $n$ varies between 123-124 for Malaysia and 176-179 for Australia. Additionally, the issues related to ethical concerns could be directly impacted by the stage of learning analtyics development in each country.

\section{Discussion}

The findings of this study suggest that academics in both Malaysia and Australia have an interest in LA although it is not yet a main concern or priority for most, and that academics are more interested in improving their teaching, rather than focussing on retention or attrition which are seen as more of an institutional concern. In previous research (e.g., West, Huijser, \& Heath, 2016), Australian institutions indicated that LA has a very high priority at the institutional level, particularly in terms of its potential impact on retention. What is evident in this study is that academics have started to become involved with activities such as using LA for analysis and decision making and reading/attending conferences/training on LA for their own professional development. These activities would seem to be directed more towards activities that could be beneficial in their own practice rather than activities that require sharing and benefiting others at large. This is in contrast to the work in the United Kingdom which takes a higher-level consortium approach (Jisc, 2017).

It would also seem that only a small percentage of academics were engaged in discussions on LA with their colleagues. From the findings discussed above, it seems as if the main beneficiaries of LA are only among academics, course/program coordinators and colleagues in communities of practice. Given LA is regarded as a catalyst for decision making at all levels (van Berneveld, Arnold, \& Campbell, 2012), be it from individual students (e.g., at-risk students) to course level actions (e.g., course planning) and institutional educational policy making (Technological Ecosystems for Enhancing Multiculturality, 2013) our research findings suggest a more introspective use of LA among academics in Australia and Malaysia. This introspection may be influenced by the lack of LA adoption in institutions or it may be due to the early stage of maturity of LA applications in many institutions (West, Huijser, \& Heath, 2016). As a result, academics who are interested in LA often pursue their research in isolation, scattered throughout the institution, and with no clear scope of LA (e.g., from the data collected to the actual use to drive change). The impact of such research may not be known to those leading institutional LA initiatives; potentially resulting in a lack of proactive monitoring or any broader discussion on the meaningful actions that should be undertaken. This approach indicates an earlier state of development than a more coordinated institutional or sector wide thinking as demonstrated by the development of position statements or codes of practice (Jisc, 2017).

In order to support the implementation of LA for teaching and learning practice, it is important to first assess the overall capacity of an institution in terms of the availability of data sources, the potential for integration of data from these data sources, and the provision of relevant professional development, as these would seem to be some of the most basic requirements for the more widespread adoption of LA by academics. When it comes to the availability of data sources which can be beneficial in supporting learning and teaching practice, Australian academics demonstrated a higher degree of willingness and/or capability to access data from the LMS's as opposed to Malaysian academics. This could be due to the following factors:

1. The majority of institutions in Australia have invested heavily in the development of LA. Although this has taken different forms and used different LMS's (e.g., Blackboard, Moodle, Canvas) it is generally more advanced and sophisticated than in Malaysia. The financial investments in LA have resulted in greater integration across and between systems, particularly with regard to the LMS and the student information system (SIS).

2. Whereas in Malaysia, only limited information about students can be found through the LMS.

3. Academics in Australia are more often required to use the LMS in teaching and learning compared to their Malaysian counterparts. 
Access to other types of data sources, such as library, learning support services, and student support services, is more challenging, with only a small percentage of academics from both countries having access to these data sources, which may impact on academics' ability to fully support student success. This could be due to low awareness and knowledge among top management about the potential these sources (or other sources that were not mentioned here) hold for LA but more likely it is a reflection of the early stage of development in LA development (West, Huijser, \& Heath, 2016). In this sense, there is a prioritisation around the integration of data sources related to both cost and benefit. It should be noted that limited access to educational data can increase the chance of critical biases and invalid analysis during the decision-making process (Ifenthaler, 2015). Having said that, limited access to educational data does not mean that all data are relevant. Furthermore, academics also raised concerns about the consequences of having a systematic integrated system, as there is a potential for the data to be collected but not used. As one Malaysian academic commented:

For LA to succeed, it needs to consider both high tech as well as high touch approaches in its implementation, because at the end of the day, assessment through discourse is what really matters and the purpose of assessment is to distinguish between students who are above the at-risk zone and students who are at the at-risk zone, and what you should do to help these at-risk students succeed (Interviewee 1, personal communication, 1 March, 2017).

As the statement above suggests, it is becoming clear that appropriate professional development is necessary to ensure academics are competent in making use of the outputs of LA reports, and being able to transform those outputs into meaningful actions that can be integrated into the teaching and learning process. The importance of professional development in relation to all aspects of LA is recognised by academics in both countries; they have indicated that they are interested in attending any training that is made available, even though it seems there is not much of it being offered.

Regarding institutions’ capacity to meet academics’ needs and expectations about the provision of LA application, academics in Malaysia and Australia had very different perceptions of what institutions provide. These differences may be related to the developmental stages of LA in those countries (West, Huijser, \& Heath, 2016). It should be noted that during the data collection process, it became evident that Australia was more advanced than Malaysia in relation to LA adoption, as some of the educational information systems are already highly integrated. It is likely that academics will be provided with more support from their institutions for LA implementation as the field continues to progress, but at the time of the Australian academic survey (2014) they had not received that support. In contrast, LA in Malaysia is still at the awareness stage, and the educational data sources are yet to be systematically integrated; thus, the academics did not have high expectations regarding LA implementation. As LA develops in Malaysia their views on what is now considered satisfactory may become unsatisfactory if institutions do not build an appropriate culture of analytics and related professional development among academics.

It is interesting to note that the weakest point for institutions' capacity lies not in the technology or the data, but rather in the foundational aspect of the LA, that is, how LA is used and what its impacts are on practice. It was clarified by some academics through the interviews that the potential use of LA is influenced by the lack of communication on the role of LA among the stakeholders. One recommendation made by the academics that would support the growth of LA as a field is having academic leaders (e.g., heads of departments, deputy deans, deans etc.) establish a sense of urgency and commitment around LA implementation. They must develop extensive and detailed information about LA including attending professional development training, creating opportunities and coordinating efforts among administrators and academic staff to embrace the culture of using data to inform decision making, and not be afraid to enforce any related policies on LA.

With respect to ethical issues, it is apparent that Malaysian academics express a higher level of concern around ethical issues compared to their Australian counterparts. However, the different rates of ethical concerns could relate to insufficient detailed policies regarding how to manage teaching and learning data. The current policies that are available (e.g., ICT policy, e-learning policy) in Malaysian higher learning institutions are very brief and reflect only the needs of institutional contexts or goals. Therefore, the academics who responded to the survey were not sure about what data would be gathered or for what purpose and what the boundaries and the potential impact might be of collecting data. In contrast, due to the more advanced stage of development, virtually all Australian universities have policies related to the 
ethical use of data, although these policies may not fully address and/or align with formal practice in using data for LA.

Given that the progress of LA development in Malaysia is still at the awareness level, and the available source systems are not yet integrated, academics are more concerned about the security of the data being used to inform educational provision, as those data may have a high value target (Seanosky, Jacques, Kumar, \& Kinshuk, 2016). In response, some universities in Malaysia have started to apply for International Organization for Standardization on information security to provide a model "for establishing, implementing, operating, monitoring, reviewing, maintaining and improving an information security management system” (International Organization for Standardization, 2005, para 1). In addition, when academics were asked to expand their thoughts regarding the ethical concerns, some of them suggested the use of anonymisation technologies for data security. These results and suggestions are consistent with the findings of Greller and Drachsler (2012), yet not much is known about their trust in such technologies. Australia, has been using educational technology and associated data for longer which has resulted in the ongoing development of a range of policies and standards across the sector around data security. These policy and standards developments have increasingly flowed through to LA approaches in terms of privacy, data security and data use. Australian academics may therefore be less concerned about data security, use and privacy than their Malaysian counterparts because there is a perception that there are more protections in place.

Higher concern about the use of data for performance management among Australian academics is understandable given that some of the educational data systems in Australia are systematically integrated, which enable the technologies to provide insights into actual teaching transactions to senior staff. The concern among academics is that increasing amounts of data related to students as well as teachers will be monitored (e.g., grades, teaching styles, supervisions, classroom management, publications etc.), and could potentially be used inappropriately in relation to performance. The same responses can be expected in Malaysia if data integration plans are developed there.

\section{Limitations of the study}

There are a number of limitations to the presented results that need to be addressed. Firstly, the sample size of this study is relatively small; hence, generalisations to the population at large cannot be made. Nevertheless, the heterogeneity of the respondents is acceptable in association with the teaching experiences, and teaching role. Additionally, the surveys were conducted in the two countries some time a part. Given the rate and nature of LA development this could present a significant limitation in terms of interpreting the results. Secondly, the study is exploratory in nature; therefore, the results are presented in a descriptive manner, which means no causal relationship analysis between variables can be performed. Due to that, the findings need to be interpreted with caution. Lastly, this study is conducted based on the perspectives of academics in Australia and Malaysia without taking into account their teaching discipline. Nonetheless, this limitation does not diminish the significance of the findings, but rather it can be taken as a recommendation for future research.

\section{Conclusions}

The findings of this research indicate academics in both Malaysia and Australia have great interest in the idea of using LA for learning and teaching practice. Despite the fact that implementation of LA in both countries is at different stages, there are some common findings across the research, such as LA activities and actions used by academics in relation to retention. While the view on the institutional capacity to support LA varies in Australia and Malaysia, it can be improved through the development and adoption of a supportive, ethical and systems integrated culture in using data and analytics by all LA stakeholders.

Although the ethical standards and cases in Malaysia may differ from those in Australia, both countries share several common values. Addressing the ethical issues may appear more difficult than managing data integration because ethics emerges differently when viewed from different angles (e.g., role, context, content specific, educational culture, etc.). Future research could consider adopting the ethics by design approach, as performed by Rodriguez-Triana et al. (2016), in order to further understand the ethical dilemma faced by academics when implementing LA for teaching and learning. 
From the discussion above, it is apparent that academics should be aware of their actions when implementing LA for classroom management, assessment, and intervention. Institutions, therefore, need to provide adequate resources for LA, such as policy, training, sophisticated analytic tools, awareness etc. which directly align with the academics' needs and are clearly spelled out in the vision of LA, so that it is appropriate for practice.

Any study on LA that involves a cross-cultures approach needs the cultural differences to be explicitly addressed and considered properly, particularly when interpreting and understanding the results of the study. Culture and context can influence the perceptions of the respondents, as is evident from this study. Therefore, when referring to any research findings from other countries specifically in relation to LA, the context of LA implementation must be well understood before it can be used as a reference in the study.

\section{Acknowledgements}

The authors would like to thank the Innovative Research Universities, the Malaysian Research Universities Network, Universiti Teknologi Malaysia (UTM) and Ministry of Higher Education (MOHE) Malaysia, for their support in making this project possible. This work was supported by the Matching Research University Grant (Q.J130000.3010.00M68) initiated by UTM and MOHE.

\section{References}

Australian Government. (2009). Transforming Australia's higher education system. Canberra: Australian Government. Retrieved from http://www.innovation.gov.au/HigherEducation/Documents/TransformingAusHigherED.pdf

Bennett, S., Agostinho, S., \& Lockyer, L. (2015). Technology tools to support learning design: Implications derived from an investigation of university teachers' design practices. Computers \& Education, 81(February 2015), 211-220. https://doi.org/10.1016/j.compedu.2014.10.016

Colvin, C., Rogers, T., Wade, A., Dawson, S., Gasevic, D., Buckingham Shum, S., Fisher, J. (2016). Student retention and learning analytics: A snapshot of Australian practices and a framework for advancement. Canberra: Australian Government Office for Learning and Teaching. Retrieved from http://www.olt.gov.au/project-student-retention-and-learning-analytics-snapshot-currentaustralianpractices-and-framework

Corrin, L., Kennedy, G., de Barba, P.G., Lockyer, L., Gasevic, D., Williams, D., Bakharia, A. (2016). Completing the loop: Returning meaningful learning analytic data to teachers. Canberra: Australian Government Office for Learning and Teaching. Retrieved from http://melbournecshe.unimelb.edu.au/_data/assets/pdf_file/0006/2083938/Loop_Handbook.pdf

Corrin, L., Kennedy, G., \& Mulder, R. (2013). Enhancing learning analytics through understanding the needs of teachers. In H. Carter, M. Gosper, \& J. Hedberg (Eds.) Electric Dreams (pp. 201-205). Retrieved from http://www.ascilite.org/conferences/sydney13/program/papers/Corrin.pdf

Cumbley, R., \& Church, P. (2013). Is “Big Data” creepy? Computer Law \& Security Review, 29(5), 601609. https://doi.org/10.1016/j.clsr.2013.07.007

Drachsler, H., \& Greller, W. (2012). Confidence in learning analytics. Proceedings of the 2nd International Conference on Learning Analytics and Knowledge, Vancouver, BC, 67-27. Retrieved from http://dspace.ou.nl/bitstream/1820/4635/1/LA_framework at_LAK12.pdf

Drachsler, H., \& Greller, W. (2016). Privacy and analytics: It's a DELICATE issue a checklist for trusted learning analytics. Proceedings of the Sixth International Conference on Learning Analytics \& Knowledge, Edinburgh, 89-98. Retrieved from http://dl.acm.org/citation.cfm?doid=2883851.2883893

Dyckhoff, A. L., Zielke, D., Bultmann, M., Chatti, M. A., \& Schroeder, U. (2012). Design and implementation of a learning analytics toolkit for teachers. Journal of Educational Technology \& Society, 15(3), 58-76. Retrieved from http://www.ifets.info/journals/15_3/5.pdf

Escotet, M. A. (2015, March 27). Purpose of cross cultural research in psychology [Blog post]. Miguel Angel Escotet. Retrieved from http://miguelescotet.com/2015/purpose-of-cross-cultural-research-inpsychology

Ferguson, R., (2012). Learning analytics: Drivers, developments and challenges. International Journal of Technology Enhanced Learning, 4(5/6), 304-317. http://dx.doi.org/10.1504/IJTEL.2012.051816 
Ferguson, R., Macfadyen, L., Clow, D., Tynan, B., Alexander, S., \& Dawson, S. (2014). Setting learning analytics in context: Overcoming the barriers to large-scale adoption. Journal of Learning Analytics 1(3), 120-144. Retrieved from http://epress.lib.uts.edu.au/journals/index.php/JLA/article/view/4077/4421

Gasevic, D., Dawson, S., Rogers, T., \& Gasevic, D. (2016). Learning analytics should not promote one size fits all: The effects of instructional conditions in predicting academic success. The Internet and Higher Education, 28(January 2016), 68-84. https://doi.org/10.1016/j.iheduc.2015.10.002

Greenhow, C., \& Gleason, B. (2014). Social scholarship: Reconsidering scholarly practices in the age of social media. British Journal of Educational Technology, 45(3), 392-402. https://doi.org/10.1111/bjet.12150

Greller, W., \& Drachsler, H. (2012). Translating learning into numbers: A generic framework for learning analytics. Educational Technology \& Society, 15(3), 42-57. Retrieved from http://www.jstor.org/stable/jeductechsoci.15.3.42

Ifenthaler, D. (2015, March 23). Learning analytics: Benefits and challenges for higher education [Blog post]. The Council Community: Four of the World's Leading Schools of Business and Management. Retrieved from https://councilcommunity.com/2015/05/23/learning-analytics-benefits-and-challengesfor-higher-education/

Ifenthaler, D., \& Tracey, M. W. (2016). Exploring the relationship of ethics and privacy in learning analytics and design: implications for the field of educational technology. Educational Technology Research and Development, 64(5), 877-880. https://doi.org/10.1007/s11423-016-9480-3

International Organization for Standardization. (2005). Information security management systems. Retrieved from https://www.iso.org/standard/42103.html

Jisc (2015a) Understanding your data. Retrieved from https://www.jisc.ac.uk/guides/understanding-yourdata

Jisc (2015b) Code of Practice for learning analytics. Retrieved from https://www.jisc.ac.uk/sites/default/files/jd0040_code_of_practice_for_learning_analytics_190515_v1 .pdf

Jisc (2017). Effective learning analytics: Helping further and higher education organisations to analyse and understand their data. Retrieved from https://www.jisc.ac.uk/rd/projects/effective-learninganalytics

Koh, E., Shibani, A., Tan, J. P., \& Hong, H. (2016). A pedagogical framework for learning analytics in collaborative inquiry tasks: An example from a teamwork competency awareness program. Proceedings of the Sixth International Conference on Learning Analytics \& Knowledge), Edinburgh, 74-83.

Lawson, C., Beer, C., Rossi, D., Moore, T., \& Fleming, J. (2016). Identification of 'at risk' students using learning analytics: The ethical dilemmas of intervention strategies in a higher education institution. Education Technology Research and Development, 64(5), 957-968. https://doi.org/10.1007/s11423$\underline{016-9459-0}$

Linacre, J. M. (1991). A user’s guide to Winsteps ${ }^{\circledR}$ Ministep Rasch-model computer programs. Retrieved from http://ifile.hkedcity.net/1/001/950/public/Secondary/EI0020070012/winsteps.pdf

Martin, F., \& Whitmer, J. (2016) Applying learning analytics to investigate timed release in online learning. Technology, Knowledge and Learning, 21(1), 59-74. https://doi.org/10.1007/s10758-015$\underline{9261-9}$

Mor, Y., Ferguson, R., \& Wasson, B. (2015). Editorial: Learning design, teacher inquiry into student learning and learning analytics: A call for action. British Journal of Educational Technology, 46(2), 221-229. https://doi.org/10.1111/bjet.12273

Pardo, A., \& Siemens, G. (2014). Ethical and privacy principles for learning analytics. British Journal of Educational Technology, 45(3), 438-450. https://doi.org/10.1111/bjet.12152

Roberts, L. D., Howell, J. A., Seaman, K. and Gibson, D. C. (2016) Student attitudes toward learning analytics in higher education. "The Fitbit Version of the Learning World”. Frontiers in Psychology 7(1959). https://doi.org/10.3389/fpsyg.2016.01959

Rodríguez-Triana, M. J., Martínez-Monés, A., \& Villagrá-Sobrino, S. (2016). Learning analytics in smallscale teacher-led innovations: Ethical and data privacy issues. Journal of Learning Analytics, 3(1), 4365. https://doi.org/10.18608/jla.2016.31.4

Rodríguez-Triana, M. J., Martínez-Monés, A, Asensio-Perez, J. I., \& Dimitriadis, Y. (2015). Scripting and monitoring meet each other: Aligning learning analytics and learning design to support teachers in orchestrating CSCL situations. British Journal of Educational Technology, 46(2), 330-343.

https://doi.org/10.18608/jla.2016.31.4 
Rubel, A., \& Jones, K. (2016). Student privacy in learning analytics: An information ethics perspective. The Information Society, 32(2), 143-159. https://doi.org/10.1080/01972243.2016.1130502

Scholes, V. (2016) The ethics of using learning analytics to categorize students on risk. Educational Technology Research and Development, 64(5), 939-955. https://doi.org/10.1007/s11423-016-9458-1

Sclater, N. (2016) Developing a code of practice for learning analytics. Journal of Learning Analytics, 3(1), 16-42. https://doi.org/10.18608/jla.2016.31.3

Sclater, N., Peasgood, A., \& Mullan, J. (2016) Learning analytics in higher education: A review of UK and international practice. Retrieved from https://www.jisc.ac.uk/sites/default/files/learninganalytics-in-he-v3.pdf

Seanosky J., Jacques D., Kumar V., \& Kinshuk (2016) Security and privacy in big data learning analytics. In V. Vijayakumar, \& V. Neelanarayanan (Eds) Proceedings of the 3rd International Symposium on Big Data and Cloud Computing Challenges (pp. 43-55). Switzerland: Springer. https://doi.org/10.1007/978-3-319-30348-2_4

Technological Ecosystems for Enhancing Multiculturality. (2013). Track 5. A promised land for educational decision making? Present and future of learning analytics. Retrieved from https://2013.teemconference.eu/tracks/learning-analytics/

Tsai, Y-S., \& Gasevic, D. (2017). The state of learning analytics in Europe. Retrieved from http://sheilaproject.eu/wp-content/uploads/2017/04/The-state-of-learning-analytics-in-Europe.pdf

van Barneveld, A., Arnold, K. E., \& Campbell, J. P. (2012). Analytics in higher education: Establishing a common language. EDUCAUSE learning initiative, 1(1). Retrieved from https://library.educause.edu/ /media/files/library/2012/1/eli3026-pdf.pdf

West, D., Heath, D., \& Huijser, H. (2016). Let’s talk learning analytics: A framework for implementation in relation to student retention. Online Learning, 20(2). Retrieved from https://olj.onlinelearningconsortium.org/index.php/olj/article/view/792

West, D., Huijser, H., \& Heath, D. (2016). Putting an ethical lens on learning analytics. Educational Technology Research and Development, 64(5), 903-922. https://doi.org/10.1007/s11423-016-9464-3

West, D., Huijser, H., Heath, D., Lizzio, A., Toohey, D., Miles, C., Searle, B., \& Bronnimann, J. (2016) Higher education teachers' experiences with learning analytics in relation to student retention. Australasian Journal of Educational Technology, 32(5), 48-60. https://doi.org/10.14742/ajet.3435

West, D., Huijser, H., Lizzio, A., Toohey, D., Miles, C., Searle, B., \& Bronnimann, J. (2016). Learning analytics: Assisting universities with student retention. Final Report (Part 1), Canberra: Australian Government Office for Learning and Teaching. Retrieved from https://olj.onlinelearningconsortium.org/index.php/olj/article/view/792/202

Corresponding author: Deborah West, Deborah.west@flinders.edu.au

Australasian Journal of Educational Technology @ 2018.

Please cite as: West, D., Tasir, Z., Luzeckyj, A., Kew,. S. N., Toohey, D., Abdullah, Z, Searle, B., Jumaat, N., Price, R. (2018). Learning analytics experience among academics in Australia and Malaysia: A comparison. Australasian Journal of Educational Technology, 34(3), 122-139.

https://doi.org/10.14742/ajet.3836 